\title{
Is cohabitation as a form of union formation a licence to intimate partner physical violence in Uganda?
}

\author{
Charles Lwanga ${ }^{1 *}$ (D), Ishmael Kalule-Sabiti ${ }^{2}$, Kamil Fuseini ${ }^{3}$, Stephen Ojiambo Wandera ${ }^{1}$, \\ Kudzaishe Mangombe ${ }^{4}$ and Fred Maniragaba ${ }^{1}$ \\ ${ }^{1}$ Population Studies, School of Statistics and Planning, Makerere University, Uganda, ${ }^{2}$ Population Studies and Demography, \\ North-West University (Mafikeng Campus) South Africa, ${ }^{3}$ Population Council-Ghana, Ghana and ${ }^{4}$ Center for Population \\ Studies, University of Zimbabwe, Zimbabwe \\ ${ }^{\star}$ Corresponding author. Email: charles.lwanga@mak.ac.ug
}

(Received 16 October 2020; revised 7 June 2021; accepted 7 June 2021; first published online 09 September 2021)

\begin{abstract}
The study examined the argument that cohabitation as a form of union increases physical violence victimization among women. The study's aim was to assess the association between physical violence and other socio-demographic factors that influence physical violence among women. Self-reported data were extracted from the 2016 Uganda Demographic and Health Survey (UDHS), with a sample of 2479 couples, from the couple file. Chi-squared tests and multivariate Firth-logit regression models were used to examine the relationship between intimate partner violence (IPV) victimization and marital status controlling for other social-demographic factors. There was no significant evidence that women in cohabiting union have a higher risk of exposure to physical violence in the Ugandan context. The risk of experiencing physical violence perpetration varied by birth cohort, with the most recent cohorts exhibiting a slightly higher risk of experiencing partner violence than previous cohorts. Significant factors found to be associated with an increased risk of experiencing IPV included being in the poorer, middle and richer compared with the poorest wealth tertile of income, residing in Eastern or Northern regions compared with the Central region, being affiliated to the Catholic faith compared with Anglican and having five or more children compared with 4 or fewer children. In conclusion, there is no evidence that physical violence is more pronounced among women in cohabiting unions compared with married women in Uganda.
\end{abstract}

Keywords: Cohabitation; Intimate physical violence; Uganda

\section{Introduction}

Violence in intimate unions has been widely researched since the 1970s and gained momentum after Makepeace pioneered a study on violence among dating couple (Makepeace, 1981). In the 1980s, cohabitation as a form of first union started rising in both developed and developing countries. Indeed, cohabitation is said to be influencing nuptiality patterns as a first co-residential union in recent times (Kiernan, 1991, 2001; Mokomane, 2005, 2013; Posel \& Rudwick, 2013). In response to these trends, recent research on family demography has become increasingly interested in understanding differences between cohabitation and marriage along several dimensions. Accompanying this paradigm shift is the argument in the emerging literature that, because of their characteristics, cohabiting unions are more violent than marital unions (Kenney \& McLanahan, 2006; Wong et al., 2016). In a study conducted in Peru, Flake reported cohabitating union as a family-level risk marker to increase a woman's likelihood of abuse (Flake, 2005). In Uganda, as in 
many parts of Africa, both violence in intimate unions and cohabitation are on the rise. For instance, the proportion of women aged 15-49 in cohabiting unions increased from $14 \%$ in 2001 to about $27 \%$ in 2011 (Uganda Bureau of Statistics (UBOS) \& ICF International Inc., 2012; Lwanga et al., 2018). Notable, however, is the increase in the proportion (27\%) of intimate partner sexual violence among women (Wandera et al., 2015).

While, on the one hand, cohabitation can offer intimacy and a family-like environment with egalitarian family structures, on the other it offers a lower level of economic consolidation and a weakened relationship short of an intrinsic barrier against union separation. As a result, less violence among women in cohabiting unions than in the married would be expected. Previous studies have demonstrated the contrary - that cohabiting women have an increased risk of experiencing violence in union than married women (Wong et al., 2016). Using data from Hong Kong medical charts between 2010 and 2014, Wong et al. also found cohabiting women to be nearly two times as likely as married women to experience multiple injuries and physical violence. Nock (1995) theorizes that the difference in the level of intimate partner violence (IPV) among cohabiting and married unions is that marriage is governed by an institution whose relationship is enforced by social and legal rules unlike cohabitation. Ellis, for instance, argues that the presence of marital norms and greater investment in union common among the married contribute to lower levels of violence in marriage (Ellis, 1989). Prior research has also been consistent. Wilson and Daly (2021), for example, argue that the social and financial costs of ending a marriage are higher than the costs of ending a cohabiting relationship, thus the marrieds invest a lot in developing strategies used to mitigate IPV.

In Uganda, where research on cohabitation and IPV is relatively new, past research on the relationship between cohabitation and violence in union has been limited. However, available studies typically involve investigating cohabitation and union dissolution (Lwanga et al., 2018). With regard to intimate violence, past research has examined the link between empowerment, partners' control and IPV (Kwagala et al., 2013, 2016; Wandera et al., 2015; Gashaw et al., 2018; Gubi et al., 2020). Elsewhere, there have been attempts to link IPV and pregnant women (Gashaw et al., 2018). However, less studied is whether being in a cohabiting union is, at first sight, a licence to intimate partner physical violence; and whether the relationship varies between birth cohort. Numerous studies have investigated the relationship between IPV among women and empowerment, modern contraception, maternal health services and partner's behaviours. However, there is no known study that has specifically focused on the study of violence against intimate female partners. The current study used self-reported data on physical aggression against currently married or cohabiting women extracted from the 2016 Uganda Demographic and Health Survey (UDHS) to examine whether IPV is more pronounced in cohabiting than in married unions; to assess whether the association varies between birth cohorts; and to examine other factors that influence physical violence among women in union.

\section{Theoretical consideration}

A number of theories and research findings on how cohabitation or marriage may influence IPV among women have been inconsistent and inconclusive. According to the social learning theory, observations of how parents and significant others in intimate relationships behave provide an initial learning of behavioural alternatives appropriate for such relationships (McLanahan \& Sandefur, 1994; Clarkberg et al., 1995; Axinn \& Arland, 1996). This theory fails to separate the effect of witnessing and experiencing violence in the natal family. However, the argument behind it suggests that, if a family of origin managed stress and frustration by using anger and violence, children from such a home environment would be at a great risk of exhibiting the same behaviours, witnessed or experienced when growing-up. This argument is consistent with the intergeneration theory of violence (Besemer, 2017). In the present context, the theory 
exposes children to violence and also teaches them the use of partner violence as being acceptable and an effective way of solving problems. This description is consistent with patriarchal norms as well as beliefs that are the foundation of male-to-female partner violence enshrined in the malepeer support theory, where anticipated rewards seem to be greater than social and non-social costs (DeKeseredy \& Schwartz, 2016). The social context theory posits that lack of social support to integrate cohabiters in society and the lower support from family and friends than for marriage, can lead to intimate violence (Skinner et al., 2002). They argue that because parents and kin are not involved in the decision to cohabit, they are unlikely to be engaged whenever there is union instability. In addition to reduced social support, cohabiters have other issues, such as lack of commitment, which inhibits couple investment and creates a context for diminishing relationship quality among cohabiters; and this contextual explanation appears to be related to the differential selection perspective. As cohabiting unions become larger and more children are born within such relationships, cohabitation may be taking on more of the functions of marriage (Cherlin, 2004; Perelli-Harris et al., 2019).

The three study hypotheses were: first, that there is no significant difference in IPV between cohabitation and marriage unions; second, that where differences do occur, they are likely to be across birth cohorts; and third, that couples with higher levels of education are likely to have lower rates of violence.

\section{Methods}

With permission from the ICF International website, data were obtained from the 2016 Uganda Demographic and Health Survey (UDHS). The DHS surveys are currently part of the worldwide survey programmes, and are a source of nationally representative data capturing individual- and household-level socio-demographic, health and sexual activity, maternal and child health, mortality, fertility, family planning and nutrition data. The Uganda DHS was implemented by the Uganda Bureau of Statistics (UBOS) with technical assistance from ICF International and funded by the United States Agency for International Development (USAID). Data were collected from a sample of female respondents aged 15-49 and male respondents aged 15-54, selected from 112 administrative districts (UBOS \& ICF, 2018). The survey was based on a probabilistic sample originating from multistage cluster sampling and was stratified by rural and urban areas. The DHS programme has been collecting information on intimate partner violence in Uganda since 2006 using a domestic violence module which addresses women's and men's experience of interpersonal violence (UBOS \& Macro, 2007).

In violence-related studies, it is more likely for one partner to report having experienced violence than for both to agree that they have ever experienced it (Szinovacz, 1983). This is based on the claim that individuals are more likely to report no violence where it has been experienced than to report violence where it hasn't. This is particularly true in a patriarchal society where anecdotal information has it that women believe that a husband is justified in beating his wife. In response to this assertion, the study's dependent variable (the indicator of violence) was constructed using couple data. Couple data were obtained by merging data from women and their partners living within the same household yielding a sample size of 2479 couples.

\section{Measures of outcome variable}

Physical intimate partner violence (IPPV) is a dummy variable created from a general question asked to all men who had ever been or who were currently in a union: 'Have you ever hit, pushed or shook, slapped, punched with fist, arm twisted, kicked or dragged, strangled or burnt, or done anything else to physically hurt your (last) (wife/partner) at times when she was not already beating or physically hurting you?' Based on the man's response, a dummy variable was created 
indicating whether he physically violated (less severe or severe) his wife or partner. In this paper, whoever perpetuated 'less severe' or 'severe' violence was coded as 1 (Yes) and as 0 otherwise.

\section{Measures of explanatory variables}

The main explanatory variable was marital status categorized as 'married' or 'living with a partner' (cohabiting). This was included in the model as a categorical variable indicating whether a women was married (coded as ' 0 ') or living with a partner (cohabiting; coded as ' 1 '). Other independent variables included birth cohort, wealth index, education, type of residence, region, children ever born, working status, religion and a wife/female partner earns more than her husband/male partner. These variables were selected based on previous studies (Wong et al., 2016). The variable 'birth cohort' was generated from current age, categorized as 2001-2005, 1996-2000, 19911995, 1986-1990, 1981-1985, 1976-1980, 1971-1975 and 1966-1970. The wealth index was based on couples' combined income grouped as poorest, poorer, middle, richer and richest. Education level was categorized as no education, primary, secondary and post-secondary but modelled as less than secondary education, those with secondary education and those with above secondary education. Religious affiliation was categorized as Catholic, Anglican, Pentecostal, Seventh Day Adventist (SDA) and other. Type of residence was grouped as rural and urban; employment was coded as working and not working. A separate dummy variable for whether the female respondent earned more than her husband/partner was grouped and re-coded as yes and no; and years since union (cohabitation or marriage) was grouped as $0-4,5-9,10-14,15-19,20-$ $24,25-29$ and $30+$ years.

\section{Statistical analysis}

Frequency distributions were used to describe and summarize the characteristics of the women in the sample. Then, the characteristics of cohabiting and married women were compared. The relationship between the dependent variable measured whether or not a woman was physically abused and explanatory variables were established at a bivariate level and tested using the chi-squared test, set at $p<0.05$. In the data, about $29 \%$ of men reported having perpetrated physical violence, indicating that this is a rare event and a possibility of biases resulting from perfect separation and the maximum likelihood estimation method (Firth, 1993; Coveney, 2008; Rahman \& Sultana, 2017). Perfect separation usually happens when the outcome variable separates the predictor variable. For these two reasons Firth's panelized logistic regression models were used with explanatory variables to examine the context of physical (IPV) associated with women in cohabiting union in comparison with the married (Heinze \& Schemper, 2002; Coveney, 2008).

The results for the panelized model are presented in the form of odd ratios (OR) with their corresponding $95 \%$ confidence intervals. While it is important to apply weights to account for complex survey design, clustering and stratification, this was not done because Firth-logit estimates do not support the svy prefix (an acronym used to instruct STATA to account for the complex survey design used in data collection). The fitted model was subjected to the link-test to examine whether the explanatory variables were specified correctly and also assess the goodness-of-fit of the model (Cleves et al., 2010; Hilbe, unpublished; Kohler \& Kreuter, 2012). The test uses the hat and _hat-squared statistic. When the model describes the data correctly and is appropriate, the hat-squared should not be significant (_hat-squared, $p>0.05$ ). Before fitting the model, a multi-collinearity test among explanatory variables (results not presented) was conducted. The variable 'duration in a relationship', though significant at bivariate level (results presented in Table 2), was found to be highly correlated with the variables 'children ever born' $(r=0.6649)$ and 'birth cohort' $(r=0.8126)$. The interest in this variable (duration in a relationship) was to create an interaction effect with the variable 'current marital status', which would help to test for selection bias. However, since the main explanatory variable (current marital status) was 
not significant, the interaction term would most likely not be significant, thus in modelling this variable was dropped. Relatedly, the variables 'children ever born' and 'birth cohort' had a positive correlation ( $r=0.5993)$, when attempts were made to remove birth cohort and keep the number of children ever-born in the model there was a negligible change in the model diagnostic test results, with _hat-squared still being insignificant. Consequently, the variable (birth cohort) was put back in the model. In statistics literature, missing data in logistic models influence regression coefficients, standard errors and statistical power. However, in this study it was assumed that missing data were missing completely at random (MCAR) and did not bias inferences (Houchens, 2015; Mohamed Reda \& Mohamed Gamal, 2018).

\section{Results}

\section{Distribution of respondents by socio-demographic characteristics}

Table 1 presents the distribution of respondents by socio-demographic factors. Nearly $29 \%$ of the male respondents in the couple sample had perpetrated physical violence against their partners. Among all women included in the couple data, approximately $41 \%$ of the respondents were affiliated to the Catholic and 3\% to other minority religious groups. The distribution of the women by wealth index shows that nearly $24 \%$ were in the poorest category and $15 \%$ were in the richest tertile of income. The majority of the women had primary education $(60 \%)$ while $6 \%$ had no education. The majority of the women (69\%) were born between 1976 and 1995, and had given birth to no more than 5 children. Approximately $18 \%$ lived in the Central and $27 \%$ in the Western regions. Nearly $23 \%$ of the women had been in union for no more than 4 years and $3 \%$ for more than 30 years. The majority of the female respondents (98\%) were working. About $11 \%$ of female respondents reported earning more than their partners/husbands and $72 \%$ said that they earned less.

\section{Differentials in experience of intimate physical violence by socioeconomic characteristics}

Table 2 presents the differentials in victimization by selected socioeconomic variables. Whether married or cohabiting, number of unions, education level and religious affiliation were not significantly associated with physical IPV. The prevalence of the perpetration of physical violence by married men was nearly $30 \%$ and about $27 \%$ by cohabiting men. Physical violence varied significantly by wealth status $\left(\chi^{2}=14.3, p=0.006\right)$, birth cohort $\left(\chi^{2}=40.6, p<0.001\right)$, type of residence $\left(\chi^{2}=4.02, p=0.045\right)$, region of residence $\left(\chi^{2}=19.13, p<0.001\right)$, number of children ever-born $\left(\chi^{2}=50.01, p<0.001\right)$ and duration in union $\left(\chi^{2}=63.5, p<0.001\right)$; but was weakly associated with women who were working $\left(\chi^{2}=2.99, p=0.083\right)$ and wives/female partners earning more than the husbands/male partners $\left(\chi^{2}=4.81, p=0.090\right)$.

\section{Multivariate results}

In isolating the net effects of each independent variable on physical IPV, a final model was built based on the identified predictors explained by the bivariate analysis. In this case, all significant independent variables at the bivariate level were included in the model, in which the dependent variable was the perpetration of physical violence in union. These included wealth index, birth cohort, type of place of residence, region of residence, children ever born, currently working and woman earns more than her husband/partner. Education level and religious affiliation were not significant; however, education level and religious affiliation were found to be significant in Uganda among married women (Wandera et al., 2018). Current marital status was not significant, but it was found to be significant in Hong Kong (Wong et al., 2016), and this is central to the main argument behind this study. Based on these studies, current marital status, education level and religious affiliation were also included in the final model. Table 3 presents the results of the 
Table 1. Percentage distribution of selected characteristics of respondents

\begin{tabular}{|c|c|c|}
\hline Characteristic & $n$ & $\%$ \\
\hline \multicolumn{3}{|l|}{ Perpetration of physical IPV } \\
\hline Never & 1770 & 71.4 \\
\hline Yes & 709 & 28.6 \\
\hline \multicolumn{3}{|l|}{ Current marital status } \\
\hline Married & 1707 & 68.9 \\
\hline Living with partner (cohabiting) & 772 & 31.1 \\
\hline \multicolumn{3}{|l|}{ Number of unions } \\
\hline One & 1407 & 68.1 \\
\hline More than one & 659 & 31.9 \\
\hline \multicolumn{3}{|l|}{ Wealth Index (combined) } \\
\hline Poorest & 589 & 23.8 \\
\hline Poorer & 536 & 21.6 \\
\hline Middle & 510 & 20.6 \\
\hline Richer & 468 & 18.9 \\
\hline Richest & 376 & 15.2 \\
\hline \multicolumn{3}{|l|}{ Educational level } \\
\hline No education & 144 & 5.8 \\
\hline Primary & 1491 & 60.1 \\
\hline Secondary & 572 & 23.1 \\
\hline Higher & 272 & 11.0 \\
\hline \multicolumn{3}{|l|}{ Birth cohort } \\
\hline $2001-2005$ & 18 & 0.7 \\
\hline $1996-2000$ & 288 & 11.6 \\
\hline 1991-1995 & 426 & 17.2 \\
\hline $1986-1990$ & 544 & 21.9 \\
\hline $1981-1985$ & 379 & 15.3 \\
\hline $1976-1980$ & 376 & 15.2 \\
\hline 1971-1975 & 275 & 11.1 \\
\hline $1966-1970$ & 173 & 7.0 \\
\hline \multicolumn{3}{|l|}{ Place of residence } \\
\hline Urban & 423 & 17.1 \\
\hline Rural & 2056 & 82.9 \\
\hline \multicolumn{3}{|l|}{ Region of residence } \\
\hline Central & 457 & 18.4 \\
\hline Eastern & 747 & 30.1 \\
\hline Northern & 612 & 24.7 \\
\hline Western & 663 & 26.7 \\
\hline
\end{tabular}


Table 1. (Continued)

\begin{tabular}{|c|c|c|}
\hline Characteristic & $n$ & $\%$ \\
\hline \multicolumn{3}{|l|}{ Religious affiliation } \\
\hline Anglican & 882 & 35.6 \\
\hline Catholic & 1007 & 40.6 \\
\hline Muslim & 282 & 11.4 \\
\hline SDA & 34 & 1.4 \\
\hline Pentecostal & 233 & 9.4 \\
\hline Other & 41 & 1.7 \\
\hline \multicolumn{3}{|l|}{ Children ever born } \\
\hline$\leq 5$ & 1449 & 58.5 \\
\hline$>5$ & 1030 & 41.5 \\
\hline \multicolumn{3}{|c|}{ Duration in union (years) (grouped) } \\
\hline $0-4$ & 578 & 23.3 \\
\hline $5-9$ & 523 & 21.1 \\
\hline $10-14$ & 430 & 17.3 \\
\hline $15-19$ & 381 & 15.4 \\
\hline $20-24$ & 292 & 11.8 \\
\hline $25-29$ & 203 & 8.2 \\
\hline $30+$ & 72 & 2.9 \\
\hline \multicolumn{3}{|l|}{ Currently working } \\
\hline No & 39 & 1.6 \\
\hline Yes & 2440 & 98.4 \\
\hline \multicolumn{3}{|l|}{ Earnings } \\
\hline More than husband/partner & 157 & 10.5 \\
\hline Less than husband/partner & 1081 & 72.3 \\
\hline About the same & 258 & 17.2 \\
\hline Total & 2479 & 100 \\
\hline
\end{tabular}

Firth-logistic model. The table shows that the odds of women in the poorer wealth tertile experiencing physical violence were 1.96 times higher $(95 \% \mathrm{CI}=1.29-2.98, p=0.001) ; 1.75$ times significantly higher for the middle income tertile; and 2.0 times higher for the richer income tertile (95\% $\mathrm{CI}=1.28-3.13, p=0.002)$ relative to women in the poorest category.

The odds of experiencing physical violence decreased among women born in 1996-2000 $(\mathrm{OR}=0.19 ; 95 \% \mathrm{CI}=0.04-0.92, p=0.04), 1991-1995 \quad(\mathrm{OR}=0.24 ; 95 \% \mathrm{CI}=0.05-1.13, p=0.07)$, $1981-1985 \quad(\mathrm{OR}=0.19 ; 95 \% \mathrm{CI}=0.04-0.90, p=0.036), 1976-1980 \quad(\mathrm{OR}=0.22 ; 95 \% \mathrm{CI}=0.05-$ $1.06, \quad p=0.059), \quad 1971-1975 \quad(\mathrm{OR}=0.25 ; \quad 95 \% \quad \mathrm{CI}=0.05-1.21, \quad p=0.084)$ and $1966-1970$ $(\mathrm{OR}=0.22 ; 95 \% \mathrm{CI}=0.04-1.11, p=0.067)$ compared with those born in 2001-2005.

Furthermore, there was increased likelihood of experiencing physical violence among women from both the Eastern $(\mathrm{OR}=2.23 ; 95 \% \mathrm{CI}=1.45-3.43, p<0.001)$ and Northern $(\mathrm{OR}=1.84 ; 95 \%$ $\mathrm{CI}=1.14-2.98, p=0.013)$ regions compared with the Central region. Women affiliated to the 
Table 2. Differentials in respondents' experience of physical IPV victimization for women in Uganda by socioeconomic characteristics

\begin{tabular}{|c|c|c|c|c|}
\hline \multirow[b]{2}{*}{ Variable } & \multirow[b]{2}{*}{$n$} & \multicolumn{2}{|c|}{ Percentage } & \multirow[b]{2}{*}{$\chi^{2}$ (p-value) } \\
\hline & & Never & Yes & \\
\hline \multicolumn{5}{|l|}{ Current marital status } \\
\hline Married & 1707 & 70.5 & 29.5 & \\
\hline Living with partner (cohabiting) & 772 & 73.4 & 26.6 & 2.2979 \\
\hline Total & 2479 & 71.4 & 28.6 & $(p=0.130)$ \\
\hline \multicolumn{5}{|l|}{ Number of unions } \\
\hline One & 1407 & 73.3 & 26.7 & \\
\hline More than one & 659 & 70.7 & 29.3 & 1.4776 \\
\hline Total & 2066 & 72.5 & 27.5 & $(p=0.224)$ \\
\hline \multicolumn{5}{|l|}{ Wealth Index (combined) } \\
\hline Poorest & 589 & 76.2 & 23.8 & \\
\hline Poorer & 536 & 66.8 & 33.2 & \\
\hline Middle & 510 & 70.2 & 29.8 & \\
\hline Richer & 468 & 69.9 & 30.1 & \\
\hline Richest & 376 & 73.9 & 26.1 & 14.388 \\
\hline Total & 2479 & 71.4 & 28.6 & $(p=0.006)$ \\
\hline \multicolumn{5}{|l|}{ Educational level } \\
\hline No education & 144 & 66.7 & 33.3 & \\
\hline Primary & 1491 & 71.0 & 29.0 & \\
\hline Secondary & 572 & 73.8 & 26.2 & \\
\hline Higher & 272 & 71.3 & 28.7 & 3.3043 \\
\hline Total & 2479 & 71.4 & 28.6 & $(p=0.347)$ \\
\hline \multicolumn{5}{|l|}{ Birth cohort } \\
\hline 2001-2005 & 18 & 55.6 & 44.4 & \\
\hline $1996-2000$ & 288 & 77.4 & 22.6 & \\
\hline 1991-1995 & 426 & 77.7 & 22.3 & \\
\hline $1986-1990$ & 544 & 73.5 & 26.5 & \\
\hline 1981-1985 & 379 & 72.8 & 27.2 & \\
\hline $1976-1980$ & 376 & 65.2 & 34.8 & \\
\hline $1971-1975$ & 275 & 66.5 & 33.5 & \\
\hline $1966-1970$ & 173 & 59.0 & 41.0 & 40.6602 \\
\hline Total & 2479 & 71.4 & 28.6 & $(p<0.000)$ \\
\hline \multicolumn{5}{|l|}{ Place of residence } \\
\hline Urban & 423 & 75.4 & 24.6 & \\
\hline Rural & 2056 & 70.6 & 29.4 & 4.0241 \\
\hline Total & 2479 & 71.4 & 28.6 & $(p=0.045)$ \\
\hline
\end{tabular}


Table 2. (Continued)

\begin{tabular}{|c|c|c|c|c|}
\hline \multirow[b]{2}{*}{ Variable } & \multirow[b]{2}{*}{$n$} & \multicolumn{2}{|c|}{ Percentage } & \multirow[b]{2}{*}{$\chi^{2}$ (p-value) } \\
\hline & & Never & Yes & \\
\hline \multicolumn{5}{|l|}{ Region of residence } \\
\hline Central & 457 & 78.3 & 21.7 & \\
\hline Eastern & 747 & 66.7 & 33.3 & \\
\hline Northern & 612 & 71.2 & 28.8 & \\
\hline Western & 663 & 72.1 & 27.9 & 19.1301 \\
\hline Total & 2479 & 71.4 & 28.6 & $(p<0.001)$ \\
\hline \multicolumn{5}{|l|}{ Religious affiliation } \\
\hline Anglican & 882 & 71.0 & 29.0 & \\
\hline Catholic & 1007 & 70.5 & 29.5 & \\
\hline Muslim & 282 & 72.3 & 27.7 & \\
\hline SDA & 34 & 85.3 & 14.7 & \\
\hline Pentecostal & 233 & 73.4 & 26.6 & \\
\hline Other & 41 & 73.2 & 26.8 & 4.3231 \\
\hline Total & 2479 & 71.4 & 28.6 & $(p=0.504)$ \\
\hline \multicolumn{5}{|l|}{ Children ever born } \\
\hline$\leq 5$ & 1449 & 76.8 & 23.2 & \\
\hline$>5$ & 1030 & 63.8 & 36.2 & 50.0185 \\
\hline Total & 2479 & 71.4 & 28.6 & $(p<0.001)$ \\
\hline \multicolumn{5}{|c|}{ Duration in union (years) (grouped) } \\
\hline $0-4$ & 574 & 78.2 & 21.8 & \\
\hline $5-9$ & 523 & 76.5 & 23.5 & \\
\hline $10-14$ & 430 & 75.1 & 24.9 & \\
\hline $15-19$ & 381 & 66.9 & 33.1 & \\
\hline $20-24$ & 292 & 58.2 & 41.8 & \\
\hline $25-29$ & 203 & 61.6 & 38.4 & \\
\hline $30+$ & 72 & 62.5 & 37.5 & 63.5718 \\
\hline Total & 2479 & 71.4 & 28.6 & $(p<0.001)$ \\
\hline \multicolumn{5}{|l|}{ Currently working } \\
\hline No & 39 & 59.0 & 41.0 & \\
\hline Yes & 2440 & 71.6 & 28.4 & 2.9957 \\
\hline Total & 2479 & 71.4 & 28.6 & $(p=0.083)$ \\
\hline \multicolumn{5}{|l|}{ Earnings } \\
\hline More than husband/partner & 157 & 63.1 & 36.9 & \\
\hline Less than husband/partner & 1081 & 71.6 & 28.4 & 4.8129 \\
\hline About the same & 258 & 70.5 & 29.5 & $(p=0.090)$ \\
\hline Total & 1496 & 70.5 & 29.5 & \\
\hline
\end{tabular}


Table 3. Odds ratio estimates for physical violence for victimization for women in Uganda

\begin{tabular}{|c|c|c|}
\hline & Odds Ratio (OR) & $95 \% \mathrm{Cl}$ \\
\hline \multicolumn{3}{|l|}{ Marital status (Ref.=married) } \\
\hline Living with partner (cohabiting) & 1.18 & $0.87,1.59$ \\
\hline \multicolumn{3}{|l|}{ Number of unions (Ref.=one) } \\
\hline More than one & 1.22 & $0.92,1.62$ \\
\hline \multicolumn{3}{|l|}{ Wealth Index (Ref.=poorest) } \\
\hline Poorer & $1.96^{\star \star}$ & $1.29,2.98$ \\
\hline Middle & $1.75^{\star \star}$ & $1.13,2.73$ \\
\hline Richer & $2.00^{\star \star}$ & $1.28,3.13$ \\
\hline Richest & 1.62 & $0.91,2.84$ \\
\hline \multicolumn{3}{|l|}{ Education level (Ref.=no education) } \\
\hline Primary & 0.79 & $0.46,1.35$ \\
\hline Secondary & 0.66 & $0.36,1.21$ \\
\hline Higher & 0.85 & $0.44,1.67$ \\
\hline \multicolumn{3}{|l|}{ Birth cohort (Ref.=2001-2005) } \\
\hline $1996-2000$ & $0.19^{\star \star}$ & $0.04,0.92$ \\
\hline 1991-1995 & $0.24^{\star \star}$ & $0.05,1.13$ \\
\hline $1986-1990$ & 0.30 & $0.06,1.38$ \\
\hline $1981-1985$ & $0.19^{\star \star}$ & $0.04,0.90$ \\
\hline $1976-1980$ & $0.22^{\star}$ & $0.05,1.06$ \\
\hline $1971-1975$ & $0.25^{\star}$ & $0.05,1.21$ \\
\hline $1966-1970$ & $0.22^{\star}$ & $0.04,1.11$ \\
\hline \multicolumn{3}{|l|}{ Place residence (Ref.=urban) } \\
\hline Rural & 1.01 & $0.69,1.48$ \\
\hline \multicolumn{3}{|l|}{ Region of residence $($ Ref. $=$ Central) } \\
\hline Eastern & $2.23^{\star \star \star}$ & $1.45,3.43$ \\
\hline Northern & $1.84^{\star \star}$ & $1.14,2.98$ \\
\hline Western & 1.41 & $0.94,2.13$ \\
\hline \multicolumn{3}{|l|}{ Religious affiliation (Ref.=Anglican) } \\
\hline Catholic & $1.39^{\star \star}$ & $1.04,1.86$ \\
\hline Muslim & 1.18 & $0.73,1.93$ \\
\hline SDA & 1.15 & $0.37,3.59$ \\
\hline Other & 0.96 & $0.32,2.88$ \\
\hline Pentecostal & 1.03 & $0.66,1.60$ \\
\hline \multicolumn{3}{|l|}{ Children ever born (Ref. $=\leq 5$ ) } \\
\hline$>5$ & $2.1^{\star \star \star}$ & $1.48,2.97$ \\
\hline \multicolumn{3}{|l|}{ Work status (Ref.=not working) } \\
\hline Working & 0.48 & $0.18,1.29$ \\
\hline
\end{tabular}


Table 3. (Continued)

\begin{tabular}{lcc}
\hline & Odds Ratio (OR) & $95 \% \mathrm{Cl}$ \\
\hline Earnings (Ref.=more than husband/partner) & & \\
Less than husband/partner & 0.83 & $0.55,1.26$ \\
About the same & 0.81 & $0.50,1.32$ \\
\hline
\end{tabular}

${ }^{\star} p<0.1 ;{ }^{* *} p<0.05 ;{ }^{* \star *} p<0.001$; Ref.=Reference Category; $\mathrm{Cl}=$ Confidence Interval.

Catholic Church were more likely to experience physical violence than those affiliated to the Anglican Church $(\mathrm{OR}=1.39 ; 95 \% \mathrm{CI}=1.04-1.86, p=0.026)$. In addition, women with six or more children were nearly two times more likely to be victims of physical violence relative to those who had fewer than six children $(\mathrm{OR}=2.1 ; 95 \% \mathrm{CI}=1.48-2.97, p<0.001)$. Although there was no significant difference between married women and those in cohabiting union, women in cohabiting relationships were 1.18 times more likely to be victims of physical violence $(95 \% \mathrm{CI}=0.87-1.59$, $p=0.287$ ). Regarding the diagnostic test of the model, the specification error results demonstrate that the Firth-logit model was well specified, as predicted by the hat and hatsq statistics (hat: $p=0.019 ;$ hatsq: $p=0.254$ ).

\section{Discussion}

This study addressed three questions: 'Is intimate partner violence (IPV) more pronounced in cohabiting than in married unions?'; 'Does the association between marital status and IPV vary across birth cohorts?'; and 'What other factors influence physical violence victimization among women in union?'. No significant difference was found in physical IPV victimization between women in cohabiting and married unions. These results contradict the findings of Wong et al. (2016) in Hong Kong, who found cohabiting women to be 2.0 times more likely to suffer from physical violence than married women. The insignificant difference in the level of physical violence experienced by cohabiting compared with married women may be understood from four arguments. The first is the transition of the Ugandan society from being highly patriarchal to become more egalitarian. This has led to status compatibility, which negates the power-control theory (of status incompatibility in intimate relationships). The second is that an increase in cohabitation is currently being experienced in Uganda, implying that marital status is undergoing social change. The implication of this, as suggested by Kiernan (2001), is that the stages of cohabitation can be described as a partnership transition. Traditionally, it was taken to be a deviant phenomenon practised by a small group of people; then as a probation stage to assess couple's commitment to marriage; later as a socially accepted alternative to marriage; and finally, as indistinguishable to marriage. In recent decades, the growing tolerance of cohabitation by the Ugandan society might also explain the insignificant difference in experience of physical violence in cohabiting compared with married women. Third, in the Ugandan context, entry into cohabitation or marriage is unlikely to depend on natural selection theory, where partners showing low level or no violence would enter marriage and those in abusive relationships enter cohabitation, as it used to be in the past. Fourth, as cohabiting unions become larger and children are born within a relationship, cohabitation may be taking much of the functions of marriage, which suppresses the would-be difference in IPV (Cherlin, 2004; Perelli-Harris et al., 2019).

It is surprising to find that women of poorer or middle income status, or those of richer income status, were more likely to suffer from physical violence than those of poorest income status. This may be explained by two arguments. First, women of poorest income status may share available family income between family expenditure and investment, or may engage in a joint family 
business with their partners, but as women become financially better-off, they may decide to be financially independent. As a result, such women may follow the equality principles for power in a relationship and if there is tension and conflict, it could increase or worsen into physical violence. Second, social status and access to income might affect the distribution of power and control within a relationship, leading to status incompatibility and reversal. If this is in favour of women in a patriarchal society, where they are taken to be inferior, it might make them vulnerable to IPV. The reason is that men can feel threatened by wives/partners who outrank them economically and socially (Buzawa et al., 2015; Meizer, 2002).

The lower levels of physical violence victimization for older cohorts compared with younger ones is not surprising and might be explained by two perspectives. The first is the life course development viewpoint. In Uganda, as with other societies, older people are more likely to possess positive relationship skills than younger ones. In addition, they are less likely to use violent behaviour when dealing with conflicts in intimate or romantic partnerships (Wekerle \& Wolfe, 1999). Second, younger women might be in different types of relationships with varying levels of intimate partner violence and commitment (Wiersma et al., 2010). The study found that women from Eastern and Northern Uganda were at a higher risk of experiencing physical violence than those in the Central region. The risk was 2.23 times for the Eastern and 1.84 times for the Northern region. This is not surprising given that these two regions have high rates of child marriage (marriage before 15 years) compared with either the Central or Western region. In this case, the inequitable gender norms that give rise to child marriages may increase the risk of conflict and physical violence (Kidman, 2017).

Some characteristics of women might increase the risk of experiencing physical violence. Results from this study show that being affiliated to the Catholic faith is a risk factor for IPV, the odds increasing by $39 \%$ compared with being affiliated to the Anglican faith. The effect of other religious denominations was not significant. This is surprising because one would expect religious people to have lower rates of IPV victimization. Increased risk among Catholics could be explained by the difference between religious affiliation and religiosity. Women could be affiliated to the Catholic faith, but attendance at religious services, which has been shown to be associated with lower rates of IPV, could be low. Women with six or more children were found to suffer from physical violence more than those with five or fewer children. Three perspectives are advanced to explain this finding. First, an increase in number of children might cause emotional and economic strain. Second, it could mean that child care attention is divided; and third, it might coincide with advance in age, which is often associated with men having extramarital relations. All these might lead to conflict and consequently physical violence. In most societies in Uganda, issues regarding physical violence are always limited to the couple and to the paternal aunt.

In summary, this study used couple data and the Firth-logit model to assess whether physical intimate partner violence victimization is more pronounced among women in cohabiting union than those in married couples. It also assessed whether the association varied across birth cohorts, and whether other factors influence physical violence among women in married and cohabiting unions. These results will be useful to inform policy dialogue and formulation, given the rising trend in domestic violence in Uganda. Future studies should endeavour to collect more data to explore further the linkage between cohabitation as a form of union, education, type of place of residence, work status, women's income being higher than husband/partner's and physical violence. There are some limitations that can be addressed for future studies. First, this study used self-reported data, and in this case IPV perpetration could be lower due to recall bias, sensitivity of reporting violence perpetration and the humiliation of doing so. Some of the perpetrators could have withheld information regarding their private experiences because of the culture of silence concerning IPV and union. Second, the data used were cross-sectional in nature and therefore the reported results are associations only, and do not imply a causative relationship.

In conclusion, there is no evidence that a woman in a cohabiting relationships has an increased risk of experiencing physical violence compared with women in marriage in Uganda. The study 
findings suggest that IPV victimization among women in Uganda is influenced by birth cohort, wealth, residing in Eastern and Northern regions, affiliation to the Catholic faith and have six or more children.

Acknowledgments. The authors extend their sincere gratitude to ICF International website for allowing them to access the 2016 Uganda Demographic and Heathy Survey (UDHS) data.

Funding. This study received no specific grant from any funding agency, commercial entity or not-for-profit organization. However, the primary author is grateful to the College of Business and Management Sciences (CoBAMS), Makerere University, for the institutional grant, as research facilitation support, for staff.

Conflicts of Interest. The authors have no conflicts of interest to declare.

Ethical Approval. This study used secondary data and the authors declare that all procedures contributing to this work conform with the ethical standards of the relevant national and institutional committees on human experimentation and with the Helsinki Declaration of 1975 , as revised in 2008.

\section{References}

Axinn W and Arland T (1996) The influence of parents' marital dissolutions on children's attitudes toward family formation. Demography 33, 66-81.

Besemer S (2017) Intergenerational Transmission of Violence. Wiley-Blackwell. URL: https://doi.org/10.1002/9781118524275. ejdj0064

Buzawa E, Buzawa, C and Stark E (2015) Responding to Domestic Violence: The Integration of Criminal Justice and Human Services. Sage Publications.

Cherlin, A. J (2004) The deinstitutionalization of American marriage. Journal of Marriage and Family 66, 848-861.

Clarkberg M, Stolzenberg R and Waite L (1995) Attitudes, values, and entrance into cohabitation versus marital unions. Social Forces 74(2), 609-632.

Cleves M, Gould W, Gutierrez R and Marchenko Y (2010) An Introduction to Survival Analysis Using Stata (Third Edition). Stata Press.

Coveney, J (2008) FIRTHLOGIT: Stata module to calculate bias reduction in logistic regression," Statistical Software Components S456948.

DeKeseredy WS and Schwartz MD (2016) Thinking sociologically about image-based sexual abuse: the contribution of male peer support theory. Sexualization, Media, and Society 2(4), 2374623816684692.

Ellis, D (1989) Male abuse of a married or cohabiting female partner: the application of socio logical theory to research findings. Violence and Victims 4, 235-255.

Firth D (1993) Bias reduction of maximum likelihood estimates. Biometrika 80(1), 27-38.

Flake DF (2005) Individual, family, and community risk markers for domestic violence in Peru. Violence Against Women 11(3), 353-373.

Gashaw BT, Schei B and Magnus JH (2018) Social ecological factors and intimate partner violence in pregnancy. PLoS One 13(3), e0194681.

Gubi D, Nansubuga E and Wandera SO (2020) Correlates of intimate partner violence among married women in Uganda: a cross-sectional survey. BMC Public Health 20(1008), https://doi.org/10.1186/s12889-020-09123-4

Heinze G and Schemper M (2002) A solution to the problem of separation in logistic regression. Statistics in Medicine 21(16), https://doi.org/10.1002/sim.1047

Houchens, R (2015) Missing Data Methods for the NIS and the SID. Agency for Healthcare Research and Quality No. $2015-01$. HCUP Methods Series Report. URL: https://www.hcupus.ahrq.gov/reports/methods/2015_01.pdf

Kenney CT and McLanahan SS (2006) Why are cohabiting relationships more violent than marriages? Demography 43(1), $127-140$.

Kidman R (2017) Child marriage and intimate partner violence: a comparative study of 34 countries. International Journal of Epidemiology 46(2), 662-675.

Kiernan K (1991) Changing marriage patterns. Journal of Social Work Practice 5(2), 123-131.

Kiernan K (2001) The rise of cohabitation and childbearing outside marriage in western Europe. International Journal of Law, Policy and the Family 15(1), 1-21.

Kohler U and Kreuter F (2012) Data Analysis Using Stata (Third Edition). Stata Press.

Kwagala B, Nankinga O, Wandera SO, Ndugga P and Kabagenyi A (2016) Empowerment, intimate partner violence and skilled birth attendance among women in rural Uganda. Reproductive Health 13, https://doi.org/10.1186/s12978016-0167-3 
Kwagala B, Wandera SO, Ndugga P and Kabagenyi A (2013) Empowerment, partner's behaviours and intimate partner physical violence among married women in Uganda. BMC Public Health 13(1), 1112.

Lwanga C, Kalule-Sabiti I and Ayiga N (2018) Cohabitation and union dissolution in central Uganda: differences between cohabitors and non-cohabitors. Journal of Biosocial Science 50(2), 178-192.

McLanahan S and Sandefur G (1994) Growing Up with a Single Parent: What Hurts, What Helps. Harvard University Press, Cambridge, MA.

Makepeace JM (1981) Courtship violence among college students. Family Relations 30, 97-102.

Meizer SA (2002) Gender, work, and intimate violence: men's occupational violence spillover and compensatory violence. Journal of Marriage and Family 64(4), 820-832.

Mohamed Reda A and Mohamed Gamal I (2018) On estimation methods for binary logistic regression model with missing values. International Journal of Mathematics and Computational Science 4(3), 79-85.

Mokomane Z (2005) A demographic and socio-economic portrait of cohabitation in Botswana. Society in Transition 36(1), 57-73.

Mokomane Z (2013) Cohabitation in Botswana: an alternative or a prelude? African Population Studies 20(1), https://doi.org/ 10.11564/20-1-385

Nock S (1995) A comparison of marriages and cohabiting relationships. Journal of the Family 16(1), 53-76.

Perelli-Harris B, Hoherz S and Lappegård T (2019) Mind the "happiness" gap: the relationship between cohabitation, marriage, and subjective well-being in the United Kingdom, Australia, Germany, and Norway. Demography 56, $1219-1246$.

Posel D and Rudwick S (2013) Changing patterns of marriage and cohabitation in South Africa. Acta Juridica : Marriage, Land and Custom 13, 169-180.

Rahman M and Sultana M (2017) Performance of Firth-and logF-type penalized methods in risk prediction for small or sparse binary data. BMC Medical Research Methodology 17(1), 33.

Skinner K, Bahr S, Crane D and Call V (2002) Cohabitation, marriage, and remarriage a comparison of relationship quality over time. Journal of Marriage Issues 23(1), 74-90.

Szinovacz M (1983) Using couple data as a methodological tool: the case of marital violence. Journal of Marriage and the Family 45, 633-644.

UBOS and ICF (2018) Uganda Demographic and Health Survey 2016. Uganda Bureau of Statistics (UBOS) and ICF

UBOS and ICF International Inc. (2012) Uganda Demographic and Health Survey 2011: Kampala, Uganda. Uganda Bureau of Statistics (UBOS) and ICF International Inc.

Uganda Bureau of Statistics (UBOS) and Macro International Inc. (2007) Uganda Demographic and Health Survey 2006. UBOS and Macro International Inc., Calverton, MD, USA.

Wandera SO, Kwagala B, Ndugga P and Kabagenyi A (2015) Partners' controlling behaviors and intimate partner sexual violence among married women in Uganda. BMC Public Health 15, https://doi.org/10.1186/s12889-015-1564-1

Wandera SO, Kwagala B and Odimegwu C (2018) Intimate partner violence and current modern contraceptive use among married women in Uganda: a cross-sectional study. The Pan African Medical Journal 30(85), https://doi.org/10.11604/ pamj.2018.30.85.12722

Wekerle C and Wolfe, D (1999) Dating violence in mid-adolescence: theory, significance, and emerging prevention initiatives. Clinical Psychology Review 19(4), 435-456.

Wiersma JD, Cleveland HH, Herrera V and Fischer JL (2010) Intimate partner violence in young adult dating, cohabitating, and married drinking partnerships. Journal of Marriage and the Family 72(2), 360-374.

Wilson M and Daly, M (2001) The Evolutionary Psychology of Couple Conflict in Registered Versus De Facto Marital Unions. In Booth A, Crouter AC and Clements M (eds) Couples in Conflict. Erlbaum Associates, Mahwah, NJ, pp. 3-26.

Wong JYH, Choi AWM, Fong DYT, Choi EPH, Wong JKS, So FL, Lau CL and Kam CW (2016) A comparison of intimate partner violence and associated physical injuries between cohabitating and married women: a 5-year medical chart review. BMC Public Health 16(1), 1207.

Cite this article: Lwanga C, Kalule-Sabiti I, Fuseini K, Wandera SO, Mangombe K, and Maniragaba F (2022). Is cohabitation as a form of union formation a licence to intimate partner physical violence in Uganda? Journal of Biosocial Science 54, 925-938. https://doi.org/10.1017/S0021932021000444 